\title{
Presentación: Dossier Perspectivas actuales sobre Historia de la Educación en el Uruguay
}

Paola Dogliotti
Fernanda Sosa
Antonio Romano

DOI: 10.21680/2596-0113.2021v4n0ID27266

Citation: Dogliotti, P.; Sosa, F. \& Romano, A. (2021). Presentación: Dossier Perspectivas actuales sobre Historia de la Educación en el Uruguay. History of Education in Latin America HistELA, 4, e27266.

Competing interests: The authors have declared that no competing interests exist.

Editor: Olivia Morais de Medeiros Neta

OPEN ACCESS
El dossier que ponemos en sus manos, Perspectivas actuales sobre Historia de la Educación en el Uruguay, organizado en el marco de la Sociedad Uruguaya de Historia de la Educación (SUHE), pone a disposición una serie de artículos diversos sobre la historia de la educación que reúnen alguna de las siguientes características o enfoques y/o relaciones entre ellos:

a. Diálogos transnacionales que intentan superar la mirada exclusivamente nacional y muestran los mecanismos de circulación de ideas, personas y/o objetos materiales, así como la actuación de instituciones y la configuración de redes de alcance transnacional. En este sentido, se pone el acento en escalas de análisis que no se reduzcan a Uruguay y que sean sensibles a la comprensión de dinámicas complejas de circulación, apropiación y reapropiación local de lo educativo.

b. Giro afectivo y estética escolar. En alguna medida algunos de los artículos abordan el llamado "giro afectivo" en los estudios de historia de la educación y colocan como objetos de estudio las emociones, sentimientos, la estética, la educación del cuerpo y las sensibilidades en la educación.

c. Estudios de género, sexualidades 0 interseccionales. En esta línea, se presentan artículos que en alguna medida abordan la historia de la educación con perspectiva de género, al pensar en la construcción de la diferencia sexual en el ámbito educativo. Por otra parte, abordan con diferentes modulaciones los vínculos entre sexualidad y educación, las masculinidades, feminidades y sexualidades en la educación, y la intersección de distintos marcadores de diferencia (género, nivel socioeconómico, edad, raza/etnia, discapacidad, diversidad sexual, entre otros), entre los aspectos más relevantes. 
Tres de los artículos que se presentan corresponden al enfoque que denominamos Diálogos transnacionales. A partir de la categoría de historias conectadas o del análisis de la configuración de un discurso que adquiere centralidad en la década del setenta en la enseñanza media, las autoras exceden el marco de análisis nacional para analizar dinámicas de circulación e intercambios. Esta perspectiva se construye en los artículos a partir de distintas fuentes: correspondencia, documentos institucionales. Se analiza además la manera en que los discursos de circulación internacional se construyen y se plasman en programas de estudio, de formación o publicaciones locales. Entendemos que conceptualmente se realizan relevantes aportes para pensar a la Educación Física, a la pedagogía ruralista uruguaya (Movimiento a favor de la Educación Rural) y al programa de enseñanza media durante la dictadura cívico militar uruguaya (1973-1985) en el marco de procesos que vinculan a los países de la región.

En Diálogos transnacionais entre Uruguai, América do Sul e Estados Unidos: a preparação de diretores de Educação Física pela Associação Cristã de Moços, Giovanna Camila Da Silva y Paola Dogliotti abordan los cursos de formación de directores de educación física promovidos por la Asociación Cristiana de Jóvenes (ACJ) en la década de 1920 en dos sedes institucionales: The Young Men's Christian Association College, en Chicago, y el Instituto Técnico Sudamericano de la Asociación Cristiana de Jóvenes, en Montevideo. Al adoptar elementos de análisis de las historias conectadas, el objeto fue analizar los tránsitos e intercambios establecidos por la ACJ entre sus sedes locales ubicados en diferentes lugares de América. Los documentos institucionales se constituyeron en fuentes privilegiadas de la investigación y les permitió a las autoras abordar un proceso de circulación de saberes y prácticas de la Asociación mediado por un negociado ejercicio de sistematización.

Pamela Reisin en su artículo ¿Hay aspectos de la reforma escolar mejicana que convenga hacer nuestros? parte de la pregunta del título, que fue planteada en una reunión de la Unión Nacional de Magisterio (U.N.M) de Uruguay en 1938 y a partir de allí indaga en la pedagogía ruralista uruguaya y sus conexiones con la educación rural mexicana (1930-1940). Al igual que el artículo anterior, mediante la metodología de historias conectadas, la autora analiza la circulación trasnacional de saberes y sus formas de apropiación tomando aportes de la teoría de internacionalización de Schriewer (1997). Para esto se vale de fuentes diversas como los boletines de asociaciones magisteriales y las publicaciones particulares de maestros.

Leonor Berná, en Agencias trasnacionales y desarrollismo en dictadura: Análisis del plan MEC-OEA para la enseñanza media básica de Uruguay en 1975, estudia el proyecto curricular para la enseñanza media que elaboraron en forma conjunta el Ministerio de Educación y Cultura y la Organización de Estados Americanos en Uruguay entre 1973 y 1975. A partir del análisis crítico de esta fuente primaria inédita y un relevamiento general de documentos de las agencias internacionales, la autora demuestra la centralidad del discurso desarrollista tecnocrático en la década de 1970. A su vez, sostiene que dentro de las nociones y propuestas de la planificación educativa abocada a la formación de recursos humanos para el desarrollo, se proyectó una pedagogía instrumental que buscó preparar al alumno para el nuevo mundo productivo. Esta perspectiva, no solo fue una de las matrices de la política educativa de la dictadura, sino que perdura hasta la actualidad.

Otros artículos abordan en alguna medida los enfoques propuestos en la convocatoria proponiendo como recortes temáticos al juego y su inscripción en el discurso escolar uruguayo a fines del siglo XIX y a la construcción de las infancias en los manuales escolares del Uruguay de principios del siglo XX. En estos casos se revisan fuentes 
como programas de enseñanza, manuales y prensa pero haciendo foco en temáticas que aportan al entendimiento de la configuración de lo escolar en el Uruguay desde perspectivas novedosas. Reviste interés la presentación de distintas miradas, discusiones y debates en torno a las categorías analizadas.

Gonzalo Pérez Monkas y Alexandre Fernandez Vaz, con su artículo, Juego y Escuela: aportes arqueológicos para pensar el juego y su inscripción en el discurso escolar en Uruguay, aborda las disputas que tuvieron lugar a fines del siglo XIX en Uruguay en torno al juego y su inscripción en los discursos escolares. Para esto se vale del primer programa de enseñanza formulado en 1897 para las escuelas públicas que incorpora como contenido para la Educación Física los "juegos gratis". El autor destaca que se trata de un momento fundacional de ese conjunto de prácticas que llegó a denominarse Educación Física y analiza de este modo las condiciones de la posibilidad de jugar en la escuela. Aborda la segunda mitad del siglo XIX con crónicas de los diarios de la época con el propósito de conocer y analizar las repercusiones del discurso civilizador sobre aquellas prácticas que plantean una mirada para el debate relacionado con los juegos en los espacios públicos, como lugar emergente y contradictorio, de donde se obtienen insumos para el surgimiento de la Educación Física.

El artículo Discursos convergentes en la construcción de la infancia sana a través de los manuales escolares, de Silvana Espiga Dorado presenta una serie de relaciones teóricas referidas a las nociones de progreso, género, moral y cuerpo sano adoptadas por las autoridades educativas uruguayas para pensar el lugar social y político de la infancia. A partir de una selección de publicaciones oficiales vinculadas a los discursos pedagógicos y médicos de principios del siglo XX, la autora los analiza desde una metodología cualitativa, relacional y situada. Concluye que en diversos documentos se encuentran argumentos clasistas y preventivos hacia la infancia; esto contribuye a pensar el manual de lectura escolar como un dispositivo que configuró y transfirió contenidos, saberes y valores en niños y niñas, en relación a: civilidad, moralidad, nacionalismo, higienismo, género, maternidad, trabajo, pobreza, ahorro, etcétera.

En definitiva, el presente Dossier Perspectivas actuales sobre Historia de la Educación en el Uruguay aporta temáticas y abordajes que llevan a repensar a la Historia de la Educación. Los artículos que se presentan realizan distintos recortes temporales que quedan comprendidos entre finales del siglo XIX y la década del setenta del siglo XX. Algunos de los artículos amplían la mirada a ámbitos de circulación transnacional de ideas aportando categorías, discusiones y enfoques teóricos que contribuyen a potenciar las miradas, aportando explicaciones que no se encuentran en las escalas nacionales de análisis. Además, se amplían campos de indagación con categorías de interés que se inscriben en debates del campo específico de Historia de la Educación. Por estos elementos el presente Dossier organiza y presenta contribuciones sustanciales. Por otro lado, los ámbitos que se analizan son diversos y contribuyen a ampliar la indagación de la disciplina. Sumado a esto, las fuentes que se analizan son heterogéneas: programas de enseñanza, manuales, presa, intercambios, documentos institucionales, boletines, publicaciones, entre otras. Los artículos presentan rigurosos análisis de dichas fuentes por lo que pensamos que también desde lo metodológico este Dossier constituye un aporte relevante a la Historia de la Educación en el Uruguay.

Cerramos esta breve presentación agradeciendo a la revista Histela, History of Education in Latin America, que abrió este espacio de reflexión académica y a las autoras y autores que presentaron sus rigurosos e interesantes trabajos. 


\section{Referências:}

Dogliotti, P., Sosa, F., \& Romano, A. (2021). Presentación: Dossier Perspectivas actuales sobre Historia de la Educación en el Uruguay. History of Education in Latin America HistELA, 4, e27266. https://doi.org/10.21680/2596-0113.2021v4n0ID27266

Dogliotti, P., \& Silva, G. da. (2021). Diálogos transnacionais entre Uruguai, América do Sul e Estados Unidos: a preparação de diretores de Educação Física pela Associação Cristã de Moços. History of Education in Latin America - HistELA, 4, e25762. https://doi.org/10.21680/2596-0113.2021v4n0ID25762

Reisin, P. (2021). “¿Hay aspectos de la reforma escolar mejicana que convenga hacer nuestros?" Pregunta planteada en una reunión de la Unión Nacional de Magisterio (U.N.M) de Uruguay en 1938. History of Education in Latin America - HistELA, 4, e25688. https://doi.org/10.21680/2596-0113.2021v4n0ID25688

Berná, L. (2021). Agencias trasnacionales y desarrollismo en dictadura: Análisis del plan MEC-OEA para la enseñanza media básica de Uruguay en 1975. History of Education in Latin America - HistELA, 4, e25765. https://doi.org/10.21680/2596-0113.2021v4n0ID25765

Pérez Monkas, G., \& Fernandez Vaz, A. (2021). Juego y Escuela: aportes arqueológicos para pensar el juego y su inscripción en el discurso escolar en Uruguay. History of Education in Latin America - HistELA, 4, e26149. https://doi.org/10.21680/2596$\underline{0113.2021 \mathrm{v} 4 \mathrm{n} 0 \mathrm{ID} 26149}$

Espiga Dorado, S. (2021). Discursos convergentes en la construcción de la infancia sana a través de los manuales escolares. History of Education in Latin America - HistELA, 4, e24723. https://doi.org/10.21680/2596-0113.2021v4n0ID24723 